\title{
Mapping soil organic carbon using auxiliary environmental covariates in a typical watershed in the Loess Plateau of China: a comparative study based on three kriging methods and a soil land inference model (SoLIM)
}

\author{
Wen Wen $\cdot$ Yafeng Wang $\cdot$ Lin Yang $\cdot$ \\ Di Liang $\cdot$ Liding Chen $\cdot$ Jing Liu $\cdot$ A-Xing Zhu
}

Received: 10 November 2013 / Accepted: 6 June 2014 / Published online: 26 July 2014

(c) Springer-Verlag Berlin Heidelberg 2014

\begin{abstract}
Detailed maps of regional spatial distribution of soil organic carbon (SOC) are needed to guide sustainable soil uses and management decisions. Interpolation methods based on spatial auto-correlations, environmental covariates, or hybrid methods are commonly used to predict SOC maps. Many of these methods perform well for gentle terrains. However, it is unknown how these methods perform to capture SOC variations in complex terrains, especially areas of which land uses are interrupted by human activities, such as the Loess Plateau of China. This study compared four interpolations or predictive methods including ordinary kriging (OK), regression kriging, ordinary kriging integrated with land-use type (OK_LU) and a soil land inference model (SoLIM). The purpose of this study is to find appropriate methods, which are suitable
\end{abstract}

\footnotetext{
W. Wen · Y. Wang $(\bowtie) \cdot$ L. Chen

State Key Laboratory of Urban and Regional Ecology,

Research Center for Eco- Environmental Sciences,

Chinese Academy of Sciences, P. O. Box 2871, Beijing 100085,

People's Republic of China

e-mail: yfwang@rcees.ac.cn

W. Wen

College of Environmental Sciences and Engineering, Peking

University, Beijing 100871, People's Republic of China

Y. Wang

State Key Laboratory of Loess and Quaternary Geology,

Institute of Earth Environment, Chinese Academy of Sciences,

Xi'an 710075, People's Republic of China

L. Yang $(\bowtie) \cdot$ A.-X. Zhu

State Key Laboratory of Resources and Environment

Information System, Institute of Geographical Sciences and

Natural Resources Research, Chinese Academy of Sciences,

Beijing 100101, People's Republic of China

e-mail: yanglin@lreis.ac.cn
}

to the complex terrain in Loess Plateau region of China. The study area was a typical watershed in Loess Plateau with complex hilly-gully terrain and various land-use types. A field sampling dataset of 200 points was partitioned into $1 / 2$ for model building and $1 / 2$ for accuracy validation in a random way. Nine environmental covariates were selected: land-use types, digital elevation model, solar radiation, slope degree, slope aspect, plan curvature, profile curvature, surface area ratio, and topographic wetness index. The mean absolute percentage error, root mean square error, and goodness-of-prediction statistic value were selected to evaluate mapping results. The results showed that the use of easily obtained environmental covariates, land-use types and terrain variables improved accuracies of SOC interpolation, which will be of interests

\author{
D. Liang \\ Department of Plant, Soil and Microbial Sciences, Michigan \\ State University, East Lansing, MI 48824, USA \\ J. Liu · A.-X. Zhu \\ Department of Geography, University of Wisconsin-Madison, \\ Madison, WI 53706, USA
}

A.-X. Zhu

School of Geography, Nanjing Normal University, Nanjing 210023, People's Republic of China 
for related research of similar environments in the Loess Plateau. SoLIM and OK_LU can be two suitable and efficient methods, which produced detailed, reasonable maps with higher accuracy and prediction effectiveness, for the study area and similar areas in the Loess Plateau.

Keywords Spatial interpolation method - Soil organic carbon - Auxiliary environmental variables - The Loess Plateau regions

\section{Introduction}

Information on the spatial distribution of soil organic carbon (SOC) is increasingly required for watershed management and ecological modeling application (Zhu et al. 2001). SOC is of fundamental importance in the chemical and physical properties of soil. On a global scale, the SOC pool is about 3.3 times the amount of the atmospheric carbon pool and 4.5 times the amount of the biotic carbon pool (Lal 2004). To map spatial variations of SOC is very meaningful for predicting and quantifying the capacity of the SOC stock. In the field of soil science, it is of specific interest to estimate the SOC stock regionally or globally because of its impact on global climate through the global carbon cycle (GCC). The pedosphere contains more carbon than the atmosphere and biosphere combined (Grace and Williams 2004). Thus, credible estimation of the SOC stock is important for understanding anthropogenic effects on the GCC and the attendant climate change (Kumar and La 2011).

Generally, SOC maps can be generated using spatial interpolation methods with point observation data. Thus, spatial interpolation methods provide an essential tool (Lin and Chen 2004; Viscarra Rossel and McBratney 1998). Generally, they can be classified mainly as three categories: methods based on spatial auto-correlations, methods based on covariates, which are related to or influence the spatial distribution of SOC, and hybrid methods (Ersahin 2003; Hosseini et al. 1994). Methods based on spatial autocorrelations, such as IDW (Inverse Distance Weighted), kriging, construct functions of spatial locations or distances of point observations to interpolate maps (Robinson and Metternicht 2006). Methods based on covariates, such as multiple regression model, derive relationships between the objective geographical element (SOC) and its environmental covariates (such as terrain parameters, vegetation conditions) to predict maps (Ersahin 2003; Hosseini et al. 1994). Recently, a soil land Inference model (SoLIM), which was developed by Zhu et al. (2001), is one representative approach based on covariates. This approach has been proved as an efficient soil-mapping method (Qi and Zhu 2003). Hybrid methods, such as regression kriging
(RK) and co-kriging, employ both spatial auto-correlations and relationships between geographical element and its covariates to predict maps (Ersahin 2003; Hosseini et al. 1994; Robinson and Metternicht 2006). It is reported that accuracies of SOC maps can be improved when using hybrid techniques with auxiliary information such as lithology, topography, etc. (Ahmed and Demarsily 1987; Lin and Chen 2004; Minasny and McBratney 2007). The Loess Plateau of China has received the most attention in China among these fragile and sensitive regions due to its vital domestic status and problematic eco-environment, which is characterized by arid, hilly and gully (Miao et al. 2012). Because vegetation restoration has been conducted since 1950 s to control soil erosion, especially, Grain-forGreen in 1999, it is greatly important to understand SOC change in Loess Plateau under the dramatic ecological restoration driven (Chen et al. 2007; Wang et al. 2010).

The spatial distribution of SOC content is continuous in nature, therefore only the continuous map can best represent the true situation of the study area. In fact, accurate and spatially continuous data across a region are usually needed by scientists to make justified interpretations, and the spatially continuous SOC data with finer resolution are needed in many cases. However, such data are usually not readily available and are often difficult and expensive to acquire, and it is still an important portion in recent research (Perry and Niemann 2008; Tramblay et al. 2010; Yao et al. 2012). Thus, estimating the values at unsampled sites using data from point observations is necessary, and spatial interpolation methods provide an essential tool to meet this need.

Most of the above methods are performed at an acceptable level for gentle terrains when producing spatially continuous surfaces of soil properties based on ground point data, but few of them performed satisfactorily for complex terrains (Sigua and Hudnall 2008). There are still existing challenges in predicting or interpolating SOC spatial distribution in Loess Plateau (Fu et al. 2009; Fu 1989). It is necessary to seek appropriate methods based on land-use modified or comprehensive consideration in topography and geomorphology.

In order to analyze the suitability of the aforementioned interpolation methods for complex terrains with various land-use types and select appropriate methods for estimating SOC, four methods including traditional ordinary kriging (OK), ordinary kriging with land-use type (OK_LU) regression kriging(RK), and SoLIM, were used to predict SOC maps for a typical watershed in Loess Plateau. Among them, $\mathrm{OK}$ is the most commonly used method (Zhu and Lin 2010). According to the existing research, SOC content in Loess Plateau regions is heavily influenced by factors such as the land-use type (Chen et al. 2007; Yao et al. 2012). Thus, OK_LU was proposed to 
Fig. 1 Location of Yangjuangou watershed in China and distribution of training dataset $\left(n_{\text {training }}=100\right)$ and validation dataset $\left(n_{\text {validation }}=100\right)$ points across the Yangjuangou watershed

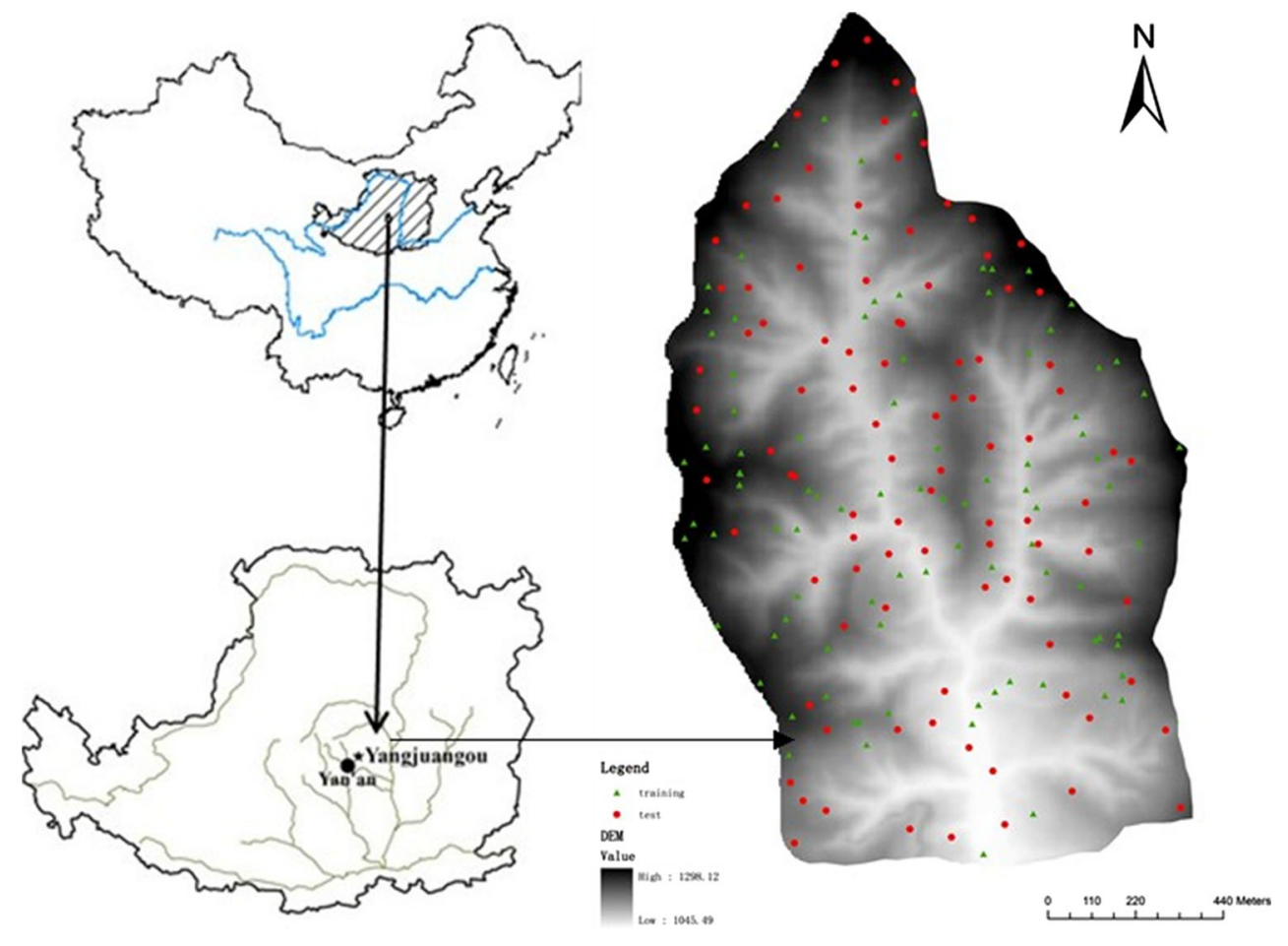

interpolate spatial variations of SOC by taking the difference of SOC content among different land-use types into account. Besides, RK and SoLIM consider environmental covariates such as slope, topographic wetness index into SOC interpolations, which have been used widely in SOC content mapping for they are known to control different soil processes and the spatial distribution of SOC content (Mueller and Pierce 2003).

Performances of these methods were assessed in terms of root mean square error (RMSE), mean absolute percentage error (MAPE) and goodness-of-prediction statistic (G) using independent validation dataset. RMSE measures the average magnitude of the error, which is squared before they are averaged, so that the RMSE gives a relatively high weight to large errors, which is most useful for undesirable large errors. MAPE is an accuracy measure based on percentage (or relative) errors, and $\mathrm{G}$ value measures effectiveness of the models.

The objectives of this study were: (1) to study SOC content variation in a region, which is small but heterogeneous in land-use types; (2) to assess the importance of using environmental covariates to improve the accuracy of SOC mapping; (3) to determine the optimal interpolation method, which fits to the hilly-gully terrain in the semiarid Loess Plateau. Fulfillment of these objectives is essential in further study of SOC of the similar watershed in the Loess Plateau area and assisting the production of soil properties maps for heterogeneous Loess Plateau areas.

\section{Materials and methods}

Study area

The study area is Yangjuangou watershed located in the center of the Loess Plateau near Yan'an, Shaanxi, China (Fig. 1). It covers an area of $2.02 \mathrm{~km}^{2}$. There are significant topographic variations within the loess hills and gully landforms of the study area. The maximum altitude difference from hilltop to gully bottom is $225 \mathrm{~m}$. The region has a semi-arid continental climate with an average annual rainfall of $535 \mathrm{~mm}$. The rainfall is concentrated mainly between July and September, and varies greatly from year to year.

The study area belongs to the loess hilly-gully region, the soil in the study area is mainly derived from loess, which is fine silt to silt in texture and weakly resistant to erosion.

In the Loess Plateau, the sunlight is strong in the daytime, and the soil began to swell after irradiation. While during the night, the temperature drops, and the soil began to shrink after cooling. Through alternative action of reciprocating temperature gap between day and night, after repeated expansion and shrink of soil particles, gradually different sizes of stone, sand and clay are formed.

In spring and winter, the northwest wind is prevailing, and the sand and gravel is blown up by the powerful wind. Among them, the big and heavy gravels cannot fly too far, so they remained in situ and created the Gobi Desert, while the tiny sands can be blown far away to create piles of deserts. 


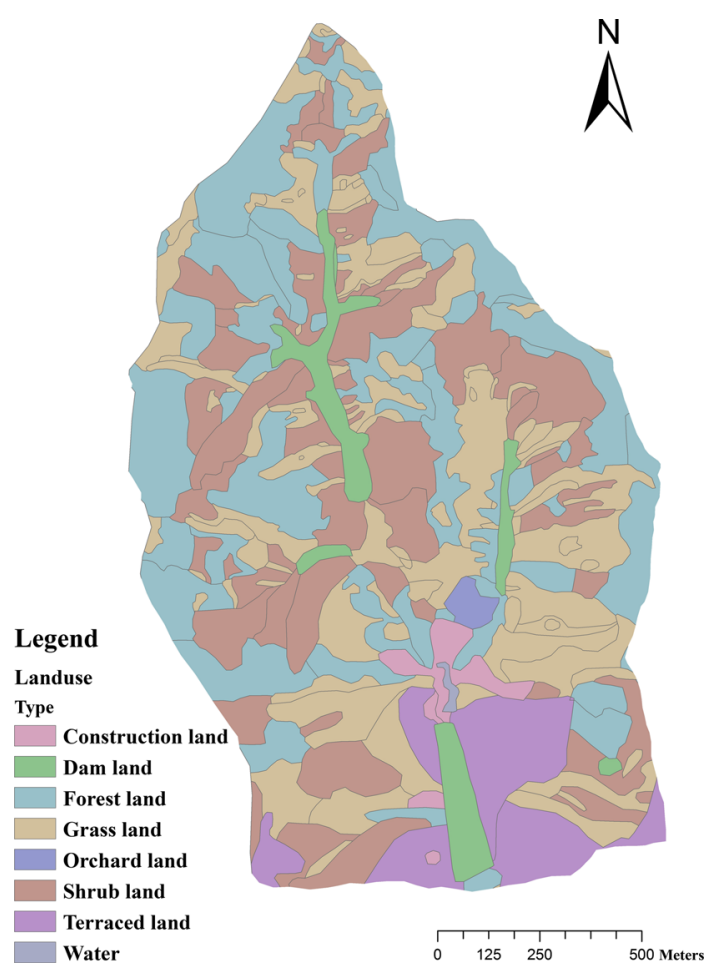

Fig. 2 Land-use type map of Yangjuangou watershed

Because the summer rain is concentrated, and surface soil is exposed for lack of vegetation protection, the soft and loose loess is strongly scoured by heavy rain, and affected by constant water erosion, eventually the landscape of mountains and valleys is formed. The terrain of study is very broken, and the land-use type is very complicated. There are more sloping fields than the flat land, blocks are both small and scattered, which is not benefited for irrigation and mechanization.

As a result of the Grain-for-Green project that was launched in 1998, most of the cultivated lands on steep slopes were abandoned for fallow or grown by planted vegetation. There is some dam land, which was built in valley, stopping the soil scoured from mountains and then deposited into farmland. Grasslands and forestlands now dominate the hill slopes, and shrubs are thriving at the bottom of the north-facing slopes.

The land-use type map of Yangjuangou watershed is shown in Fig. 2, which was interpreted from the 10-mresolution remote-sensing image of ALOS in 2000, and auxiliary artificial investigation was implemented to check and amend the land-use map. There are eight land-use types: shrubland, forestland, slope cropland, grassland, terrace, dam land, water bodies and residential land. Among these land-use types, forestland covers the largest area of $0.63 \mathrm{~km}^{2}$, followed by grassland and shrubland that are 0.51 and $0.50 \mathrm{~km}^{2}$, respectively.
Soil samples data

Field sampling was carried on in 2011. Sampling points were selected at least three different positions from top, middle and bottom of slopes for each land-use type. Latitude and longitude coordinates of each point were obtained using GPS and the detailed information of each sample including slope aspect, slope degree and land-use type was recorded. Soil samples in $0-30 \mathrm{~cm}$ depth were collected with a soil core auger (Eijkelkamp, diameter $60 \mathrm{~mm}$ ). Three cores taken within a $1 \mathrm{~m} \times 1 \mathrm{~m}$ square were combined in one sample. 200 soil-sampling samples were finally collected, including 66 soil samples of forestland, 40 soil samples of shrub land, 46 soil samples of grassland, 10 soil samples of slope cropland, 24 soil samples of dam land, and 14 soil samples of terrace land. Locations of these data points are shown in Fig. 1.

Once extracted from the ground, the samples were placed in aluminum cans with tight-fitting lids. Soil samples were analyzed at State Key Laboratory of Urban and Regional Ecology, Research Center for Eco-Environmental Sciences, Chinese Academy of Sciences. After being airdried and grinded in the laboratory and sieved through a 2-mm screen, the samples were weighed and packed. Then indoor experimental analysis was carried out. The method of outside heating by $\mathrm{K}_{2} \mathrm{Cr}_{2} \mathrm{O}_{4}$ was applied to measure the SOC content of samples.

To produce a spatially continuous surface and evaluate the performance of each interpolation method, the whole dataset of 200 samples was divided randomly into training dataset $(n=100)$ and validation dataset $(n=100)$ by one of the Geostatistical Analyst tools called "subset features" in ArcGIS software (version 10.0, ESRI Inc., Redlands, CA, USA). The training dataset was used to predict spatial variations of SOC, while the validation dataset was used to evaluate performances of all the interpolation models. In order to minimize the impact of distribution of the training dataset on the performance of the methods, the building of datasets (including training dataset and validation dataset) was conducted three times (S1-S3). For each time, the spatially continuous surface was produced by four interpolation approaches and the performance was assessed accordingly. The final results are average of results of the three times.

\section{Environmental covariates}

Based on the cognition of the soil-environmental covariates relationship in the study area, as well as the existing research results of the relationship between SOC content and environmental covariates, nine variables were chosen to depict the environment characteristics in the SoLIM 
method: land-use type, digital elevation model (DEM), solar radiation, slope degree, slope aspect, plan curvature, profile curvature, surface area ratio (SAR), and topographic wetness index (TWI).

Among all selected terrain variables, DEM usually has a negative correlation with SOC content (Lian Gang et al. 2006; Qiu et al. 2004). Slope degree reflects the local terrain surface tilt, which has a direct relationship with the degree of surface soil stability and exhaust ability of the surface flow, thereby affecting the content of SOC (Huang Ping et al. 2009). The slope aspect is defined as the horizontal projection of the slope normal line, which determines sunshine duration and solar radiation intensity that can be accepted by the ground, thus influences the growth status of vegetation, even the accumulation and decomposition of SOC content (Zhong et al. 2006). Curvature is the characterization of terrain attributes of convex-concave shape changes in each section direction of local topography, which can be used to depict the converge or diffusion of surface streams, the intensity of soil erosion, etc., and also affects the spatial distribution of SOC content (Zhou Bin and Wang 2003). Surface area ratio (SAR) is the ratio of surface area and the projection area, which depicts the ups and downs of internal shape of grid, and can be used to distinguish between mountains and plains with different terrain features (Jenness 2004). The different surface morphology of the ups and downs must inevitably lead to the differences of accumulation and decomposition process of surface SOC content. Topographic wetness index (TWI) can quantitatively reflect the comprehensive condition of soil water storage and drainage, and similarly affects SOC content (Lian Gang et al. 2006).

In the study area, altitude, longitude and latitude were obtained a GPS receiver with 5-m precision, and later imported into a geographic information system (ArcGIS 10.0) as Albers coordinates. A 5-m-resolution DEM was derived from a 1:10,000 scale topographic map using ArcGIS 10.0. The slope degree and aspect were measured with a geological compass. The plan curvature, profile curvature and solar radiation were generated by Arcgis 10.0 based on DEM while the solar radiation is the yearly sum of radiation. Surface area ratio (SAR) was the ratio of surface area of a grid and projected area, which depicts ups and downs of the terrain inside a grid and can be used to distinguish mountains and plains with different terrain features, because the difference exists in the accumulation and decomposition process of SOC. SAR was generated by the algorithm presented by Jenness (2004), and the topographic wetness index (TWI) was generated by the SimDTA 1.0 software with Qin's multiple-flow-direction algorithm (Qin et al. 2007). For the nine maps of environmental covariates, the scale of them is $1: 10,000$, and the resolution of them is $5 \mathrm{~m}$.
Interpolation methods

Four methods were applied for interpolation. The OK and OK_LU method were conducted using ArcGIS 10.0. For the RK methods, the linear regression functions were established in SPSS 16.0, and the prediction of the continuous spatial surface was conducted by ArcGIS 10.0; as for the SoLIM method, it was generated by the SoLIM software (http://SoLIM.geography.wisc.edu/software/email_ address.aspx).

\section{Ordinary kriging $(O K)$}

Ordinary kriging $(\mathrm{OK})$ is a type of kriging used to estimate the value of a random variable at one or more unmeasured points (Kumar and La 2011) and a spatial interpolation estimator $\hat{Z}\left(x_{0}\right)$ used to find the best linear unbiased estimate (at non-sampled location) of a second-order stationary random field with an unknown constant mean as follows:

$\hat{Z}\left(x_{0}\right)=\sum_{i=1}^{n} \lambda_{i} Z\left(x_{i}\right)$

where $\hat{Z}\left(x_{0}\right)$ is kriging estimate at non-sampled location $x_{0}$, $Z\left(x_{i}\right)$ is sampled value at location $x_{i}$, and $\lambda_{i}$ is the weighting factor for $Z\left(x_{i}\right)$.

The estimation error is

$\hat{Z}\left(x_{0}\right)-Z\left(x_{0}\right)=R\left(x_{0}\right)=\sum_{i=1}^{n} \lambda_{i} Z\left(x_{i}\right)-Z\left(x_{0}\right)$

where $Z\left(x_{0}\right)$ is unknown true value at $x_{0}$, and $R\left(x_{0}\right)$ is estimation error. For an unbiased estimator, the mean of the estimation error must equal zero. Therefore,

$E\left\{R\left(x_{0}\right)\right\}=0$

and

$\sum_{i=1}^{n} \lambda_{i}=1$

Minimum variance of estimation error is required for solving the interpolation problem by kriging. The minimization of the estimation error variance under the constraint of unbiasedness leads to a set of equations for the weighting factors, $\lambda_{i}$, which can be solved by an optimization routine (Chowdhury et al. 2010). The details on the ordinary kriging technique and related information can refer to Goovaerts et al. (Goovaerts et al. 2005), and the specific details on the software routines can refer to the Geostatistical Software Library (GSLIB) and Users Guide (Kupfersberger et al. 1998). 
Ordinary kriging integrated with land-use type (OK_LU)

Several studies have indicated that land-use type information is significantly related to the spatial pattern of soil property variations (Basaran et al. 2008; Hu et al. 2007). In our study area, the landscape is complicated and associated with various land-use types. In order to explore how landuse type information will assist mapping SOC spatial distribution, this method (OK_LU) incorporates the categorical land-use type information for spatial interpolation of SOC. The specific method includes the following two steps:

Firstly, the average SOC content values for each landuse type were calculated. The soil organic carbon content value of each training sample point $Z\left(X_{k j}\right)$ is then divided into mean value $\mu\left(T_{k}\right)$ of the same type and deviation $R\left(X_{k j}\right)$, which can be expressed as

$Z\left(X_{k j}\right)=\mu\left(T_{k}\right)+R\left(X_{k j}\right)$

where $Z\left(X_{k j}\right)$ is the training sample's soil organic carbon content; $\mu\left(T_{k}\right)$ is the mean value of soil organic carbon content of the same land-use type; $R\left(X_{k j}\right)$ is the deviation. $R\left(X_{k j}\right)$ is regarded as a new regional variable, which is interpolated with ordinary kriging;

Secondly, the interpolation of deviation $R\left(X_{k j}\right)$ is finished. The predicted soil organic carbon content value of sample is the sum of the mean value $\mu\left(T_{k}\right)$ of the SOC content of the same land-use type and the estimated deviation $R^{\prime}\left(X_{k j}\right)$.

$Z \prime\left(X_{k j}\right)=\mu\left(T_{k}\right)+R \prime\left(X_{k j}\right)$

\section{Regression kriging (RK)}

RK is a spatial interpolation technique that combines the regression of the dependent variable on auxiliary variables with the kriging of the regression residuals (Hengl et al. 2007; Zhu and Lin 2010). The target variable SOC was fitted with each auxiliary dataset using the linear regression. By detrending the regression predictions, the residuals were geostatistically analyzed and interpolated using ordinary kriging, and finally the regression predictions and interpolated residuals were summed. In RK, the auxiliary datasets in the regression were the same as in the liner regression ( $\mathrm{Bi}$ et al. 2008). The function used to perform RK is given as below in Eq. (7) (Hengl et al. 2007):

$\hat{Z}\left(s_{o}\right)=\hat{m}\left(s_{0}\right)+\hat{e}\left(s_{0}\right)=\sum_{k=0}^{p} \hat{\beta}_{k} \cdot q_{k}\left(s_{0}\right)+\sum_{i=1}^{n} \lambda_{i} \cdot e\left(s_{i}\right)$

where $\hat{m}\left(s_{0}\right)$ is the fitted drift, $\hat{e}\left(s_{0}\right)$ is the interpolated residual, $\hat{\beta}_{k}$ are the estimated drift model coefficient $\left(\hat{\beta}_{0}\right.$ are the estimated intercept), $\lambda_{i}$ are kriging weights determined
Table 1 Dumb variables for land-use types

\begin{tabular}{llllll}
\hline Category & T1 & T2 & T3 & T4 & T5 \\
\hline S1 (Forestland) & 1 & 0 & 0 & 0 & 0 \\
S2 (Grassland) & 0 & 1 & 0 & 0 & 0 \\
S3 (Shrubland) & 0 & 0 & 1 & 0 & 0 \\
S4 (Terrace) & 0 & 0 & 0 & 1 & 0 \\
S5 (Slope cropland) & 0 & 0 & 0 & 0 & 1 \\
S6 (Dam land) & 0 & 0 & 0 & 0 & 0 \\
\hline
\end{tabular}

Table 2 Significance test of each regression factors

\begin{tabular}{llll}
\hline & Sig. & & \\
\cline { 2 - 4 } & Y1 & Y2 & Y3 \\
\hline Constant & 0.015 & 0.002 & 0.000 \\
T1 & 0.000 & 0.009 & 0.000 \\
T2 & 0.000 & 0.047 & 0.000 \\
T3 & 0.000 & 0.019 & 0.022 \\
T4 & 0.000 & 0.024 & 0.000 \\
T5 & 0.000 & 0.017 & 0.000 \\
Variable 1 & 0.000 (TWI) & 0.028 (SAR) & 0.024 (Solar \\
Variable 2 & 0.009 & & radiation) \\
& (Slope) & curve) & 0.032 (Slope) \\
\hline
\end{tabular}

by the spatial dependence structure of the residual and where $e\left(s_{i}\right)$ is the residual at location $s_{i}$.

The nine variables were used as independent variables when constructing regression function for RK. Except the construction land and water area, there are six original land-use types. S1-S6 are used to indicate six land-use types. Since land-use type is a categorical variable, preprocess on this variable was conducted. Five dumb variables of T1, T2, T3, T4, and T5 are set in the SPSS. The setting of parameters was displayed in Table 1. For example, while the land-use type is $\mathrm{S} 1, \mathrm{~T} 1=1$, $\mathrm{T} 2=\mathrm{T} 3=\mathrm{T} 4=\mathrm{T} 5=0$, and so forth.

In the regression analysis, five variables of $\mathrm{T} 1, \mathrm{~T} 2, \mathrm{~T} 3$, $\mathrm{T} 4$, and $\mathrm{T} 5$ that represent the variable of land-use types as a whole were put in block 1, and variable selection method was set as compulsory (Enter) in. The other eight variables were in the second block with variable selection method of stepwise regression (Stepwise). The final regression functions of three datasets were established as both the function and the parameters passed through the test of significance $(P<0.05)$ (Table 2).

\section{Soil land inference model (SoLIM)}

Soil land inference model (SoLIM) is a predictive approach to infer soil mapping based on environmental variables and 
relationships between soil and its environment (Zhu et al. 1997, 2001). Under the SoLIM framework, Liu et al. (2012) proposed a method based on "individual representativeness" of each sample to predict soil properties (Liu et al. 2012). The basic idea is as follows. Based on the soil-landscape model (Hudson 1992) and case-based reasoning idea (Aamodt and Plaza 1994), each sample contains corresponding relationships between soil properties and environment conditions. Under the assumption that the more similar is environment condition between two locations the more similar soil property values will be, each sample can be considered as a representative over locations with similar environmental conditions (Hudson 1992; McBratney et al. 2003). Moreover, the level of representativeness of an individual sample for an unsampled location can be approximated by computing the similarity in environmental conditions between the two locations. Based on this "individual representativeness" concept, soil property values at unsampled locations can be estimated based on the environmental similarity to individual samples, which consist of three major components: (1) selecting environmental variables and characterizing environmental conditions; (2) calculating environmental similarity; (3) estimating soil property value based on the environmental similarity.

\section{Spatial structure analysis indices}

Nugget over sill ratio (N/S), which defines the proportion of short-range variability that cannot be described by a geostatistical model based on a variogram, has been used to quantify the strength of spatial structure (Pei et al. 2010). An N/S ratio of 0.3 means that $30 \%$ of the variability consists of unexplainable or random variation. N/S ratio was divided into three categories $(>0.6,0.3-0.6$, and $<0.3)$ to classify the strength of spatial structure by Cambardella and Karlen. The N/S ratio $<0.3$ indicated strong or distributed in patches, between 0.3 and 0.6 denoted moderate, and $>0.6$ indicated weak spatial dependence (Cambardella and Karlen 1999).

In addition to N/S, the ratio of sill to the sum of sill and nugget variance $\mathrm{S} /(\mathrm{N}+\mathrm{S})$ as discussed by Cambardella et al. (1994), was also calculated. A ratio approaching one means a strong spatial pattern, whereas, a ratio approaching zero indicates that there is no spatial pattern (Ge et al. 2007b).

Evaluation indices

Performance of the estimations was tested using six statistical indices as follows:

1. Mean absolute percentage error (MAPE) (Li and Heap 2011). The MAPE was used to assess prediction bias.
2. Root mean square error (RMSE). RMSE was used as a measure of prediction precision.

3. Goodness-of-prediction statistic (G) (Kravchenko and Bullock 1999). For $G$ value, if $G=1$, it means the predicted value and measured value are completely consistent.

4. The variance accounted for (VAF) (Mirbagheri et al. 2000). It is defined as one minus the ratio of the variance of the model's error in estimating SOC to the variance of the SOC data.

5. The adjusted determination coefficient (Adj- $\left.R^{2}\right)$ (Marquíez et al. 2003). It compensates for this optimistic trait in the determination coefficient by taking into account the size of the sample and the number of prediction variables. Unlike $R^{2}$, the adjusted determination coefficient does not necessarily increase when additional variables are added to an equation.

These are the metrics that estimate the deviation of estimations from observations. The model with the lowest MAPE and RMSE, while the VAF, Adj- $R^{2}, G$ values are closer to 1 were considered as the least biased. The six indices are calculated as follows:

$\mathrm{MAPE}=\frac{1}{n} \sum_{i=1}^{n}|(P i-O i) / O i|$

$\mathrm{RMSE}=\left[\frac{1}{n} \sum_{i=1}^{n}\left(P_{i}-O_{i}\right)^{2}\right]^{1 / 2}$

$G=1-\left[\sum_{i=1}^{n}\left(P_{i}-O_{i}\right)^{2} / \sum_{i=1}^{n}\left(O_{i}-\bar{O}\right)^{2}\right]$

$\% \mathrm{VAF}=100 \times\left[1-\frac{\sum^{n}\left(O_{i}-P_{i}\right)^{2}}{\sum_{1}^{n} O_{i}^{2}}\right]$

where $n$ is the number of validation points, $P_{i}$ is the predicted value at point $i, O_{i}$ is the observed value at point $i$, and $\overline{\mathrm{O}}$ is the sample arithmetic mean.

\section{Results}

General statistics for SOC content

As shown in Table 3, the SOC content for the top 30-cm soil layer varies from $1.20 \mathrm{~g} \mathrm{~kg}^{-1}$ to $5.35 \mathrm{~g} \mathrm{~kg}^{-1}$ under different land-use type. The variance among different landuse types is $82.70 \%$. The order of the mean value of SOC content is as follows: forestland $>$ shrub land $>$ grassland $>$ dam land $>$ slope cropland $>$ terrace. The significance test for SOC content among different land-use types was demonstrated in Table 3. For terrace, the mean value of SOC content is lowest and significantly different from 
Table 3 Statistic parameters of SOC in the six land-use types

\begin{tabular}{lllllll}
\hline $\begin{array}{l}\text { Land-use } \\
\text { type }\end{array}$ & $\begin{array}{l}\text { Soil } \\
\text { sample }\end{array}$ & \multicolumn{2}{l}{ SOC content $\left(\mathrm{g} \mathrm{kg}^{-1}\right)$} & $\begin{array}{l}\text { Variance } \\
(\%)\end{array}$ \\
\cline { 3 - 6 } & & Mean & $\begin{array}{l}\text { Standard } \\
\text { error }\end{array}$ & Min. & Max. & \\
\hline Forestland & 66 & $3.27^{\mathrm{A}}$ & 0.82 & 1.80 & 5.31 & 67.70 \\
Shrubland & 40 & $3.03^{\mathrm{AB}}$ & 0.90 & 1.20 & 5.08 & 82.50 \\
Grassland & 46 & $2.99^{\mathrm{AB}}$ & 0.99 & 1.25 & 5.34 & 99.30 \\
Dam land & 10 & $2.93^{\mathrm{B}}$ & 0.62 & 2.04 & 4.20 & 42.30 \\
$\begin{array}{l}\text { Slope } \\
\text { cropland }\end{array}$ & 24 & $2.91^{\mathrm{B}}$ & 0.95 & 1.53 & 5.02 & 94.70 \\
$\begin{array}{l}\text { Terrace } \\
\text { Total }\end{array}$ & 14 & $2.28^{\mathrm{C}}$ & 0.64 & 1.30 & 3.27 & 44.60 \\
\hline
\end{tabular}

The capital letters represent the significant level is $p=0.05$

all of other land-use types because of the little biomass input and frequent human disturbance. The significant difference also exists between forestland and slope cropland, forestland and dam land. We can conclude from the Table 3 that there is a difference in SOC content among different land-use types.

The regression functions for RK

The Models' degree of fitting is $R^{2}=0.178,0.158,0.161$, respectively. The regression functions of three times employed by the RK method to estimate the spatial distribution of SOC content were given below:

$$
\begin{aligned}
\mathrm{Y} 1= & 1.244+0.313 \times \mathrm{T} 1+0.326 \times \mathrm{T} 2+0.399422 \\
& \times \mathrm{T} 3-0.346 \times \mathrm{T} 4+0.340 \\
& \times \mathrm{T} 5+0.205 \times \mathrm{TWI}+0.020 \times \mathrm{Slope} \\
\mathrm{Y} 2= & 1.345+0.011 \times \mathrm{T} 1-0.149 \times \mathrm{T} 2+0.344 \\
& \times \mathrm{T} 3-0.754 \times \mathrm{T} 4-0.014 \times \mathrm{T} 5+1.439 \\
& \times \mathrm{SAR}-0.318 \times \mathrm{Plancurve} \\
\mathrm{Y} 3= & 3.947+0.156 \times \mathrm{T} 1+0.022 \times \mathrm{T} 2-0.545 \\
& \times \mathrm{T} 3-0.346 \times \mathrm{T} 4+0.340 \times \mathrm{T} 5-5.564 \times 10^{-7} \\
& \times \text { Solar radiation }-0.001 \times \text { Slope }
\end{aligned}
$$

For the environmental variables entered into the regression equations of three datasets were different based on different sample sets as shown in formulas (12)-(14), it means that the result of RK is imperfect. This is mainly because the land-use type information was introduced into the regression functions compulsory considering it as a main controlling factor for SOC in the study area.

Spatial structure of SOC

In previous SOC mapping studies, the spherical, Gaussian and exponential have been the most widely used models in
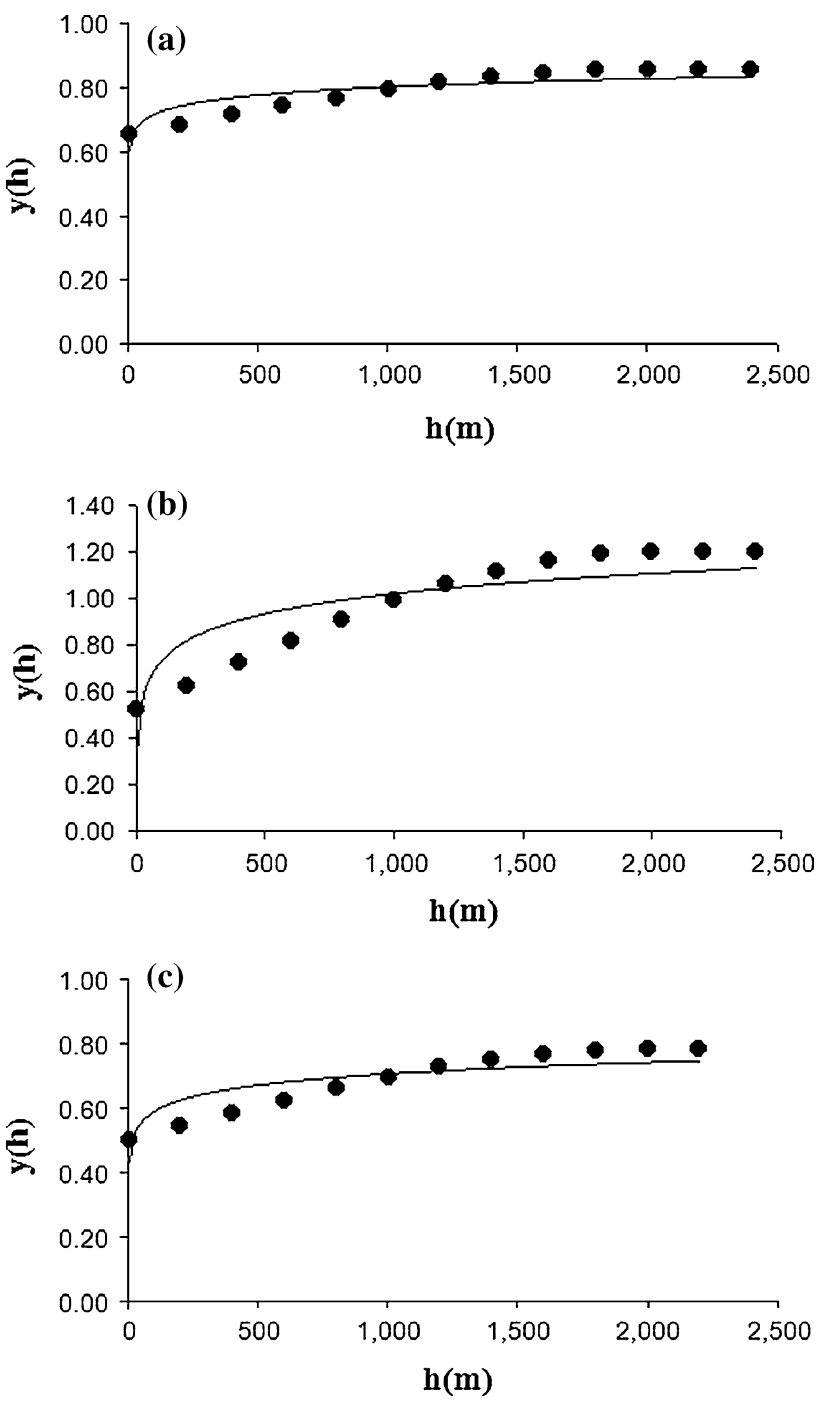

Fig. 3 Experimental (dots) and modeled (lines) semi-variograms. a $\mathrm{SOC}(\mathrm{OK}), \mathbf{b}$ deviation of SOC (OK_LU), $\mathbf{c}$ regression residue of $\mathrm{SOC}(\mathrm{RK})$

Table 4 Semi-variogram models for the soil organic carbon (SOC), ordinary kriging with land-use type (OK_LU) residuals, and regression kriging (RK) residuals

\begin{tabular}{llll}
\hline Parameter & SOC & OK_LU residuals & RK residuals \\
\hline Model & Spherical & Spherical & Spherical \\
Major range/m & 2,000 & 2,000 & 2,000 \\
$\mathrm{~N} /\left(\mathrm{km} \mathrm{m}^{-2}\right)^{2}$ & 0.60 & 0.52 & 0.45 \\
$\mathrm{~S} /\left(\mathrm{km} \mathrm{m}^{-2}\right)^{2}$ & 0.86 & 1.20 & 0.78 \\
$\mathrm{~N} / \mathrm{S}$ & 0.70 & 0.43 & 0.58 \\
$\mathrm{~S} /(\mathrm{N}+\mathrm{S})$ & 0.41 & 0.60 & 0.58 \\
\hline
\end{tabular}

fitting semi-variograms (Pei et al. 2010). Here, we use the exponential model to fit the experimental SOC semi-variogram. The experimental semi-variogram of the present 

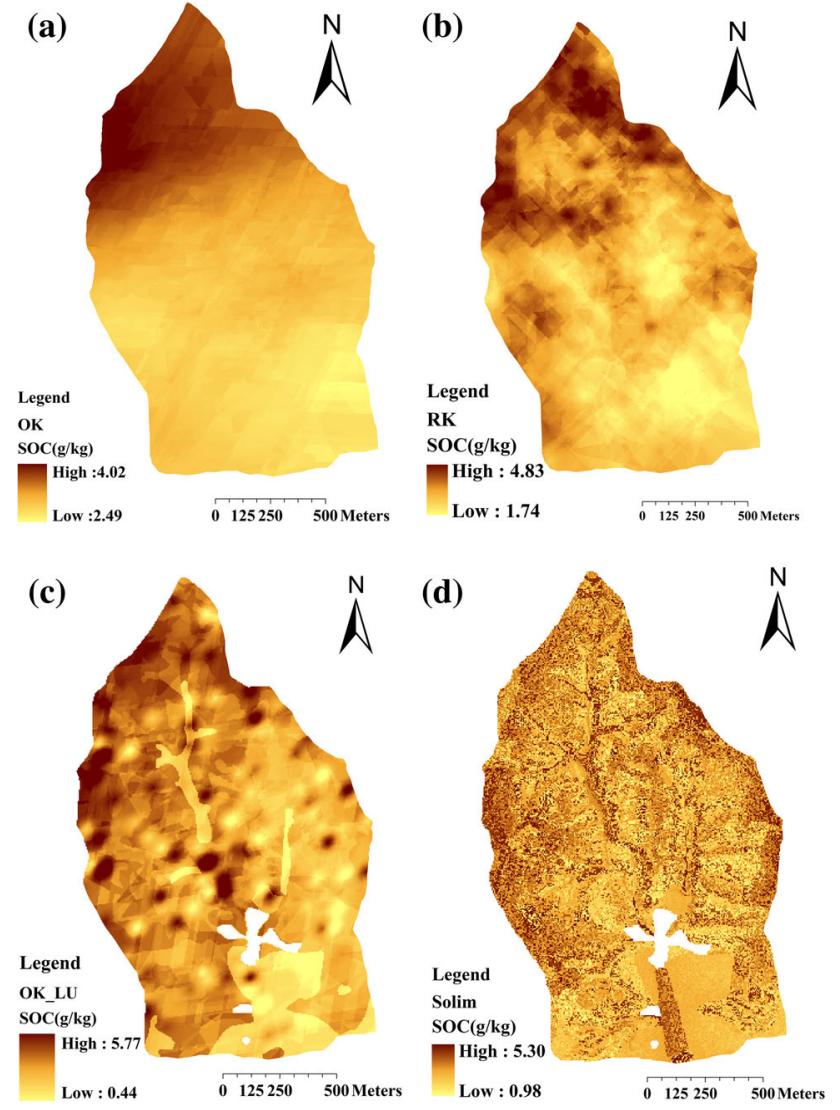

Fig. 4 Maps of the estimated soil organic carbon (SOC) content for the surface $(0-30 \mathrm{~cm})$ soil of Yangjuangou watershed using different methods: a (OK), b (RK), c (OK_LU), d (SoLIM)

study, including the original SOC data (applied in OK), the SOC deviation (applied in OK_LU), and regression residue of SOC (applied in RK) together with the fitted exponential models is shown in Fig. 3 and Table 4. The experimental variogram model shows that SOC content for the surface $30-\mathrm{cm}$ soil layer was spatially auto-correlated. This model describes the spatial variation of the SOC content. The range corresponds to the spatially correlated portion of the semi-variogram.

As displayed in the Table 4, N/S differs among different methods. The N/S of OK (0.70) is more than 0.6 , while that of OK_LU deviation (0.43) and RK residuals (0.58) are less than 0.6. Lower N/S ratio represents the strong spatial dependence (Cambardella and Karlen 1999; Lado et al. 2008). The results displayed support to the strong spatial dependence of data analyzed by the hybrid approach OK_LU to estimate the SOC content in this study area.

For $\mathrm{S} /(\mathrm{N}+\mathrm{S})$, it shows the strong spatial pattern with values of ratio for the SOC, OK_LU deviation and RK residuals of $0.41,0.60$ and 0.58 , respectively. Thus, it reveals that OK_LU deviation has stronger spatial patterns than others, and this conclusion also sustains the reliability of OK_LU.
Table 5 Correlation analysis between the measured values and the estimated values

\begin{tabular}{lllll}
\hline & OK & RK & OK_LU & SoLIM \\
\hline MAPE & 0.250 & 0.124 & 0.060 & 0.052 \\
RMSE & 0.520 & 0.448 & 0.315 & 0.329 \\
$G$ & 0.791 & 0.794 & 0.878 & 0.886 \\
$\%$ VAF & $57 \%$ & $61 \%$ & $72 \%$ & $75 \%$ \\
Adj. $R^{2}$ & 0.326 & 0.278 & 0.519 & 0.537 \\
\hline
\end{tabular}

SOC mapping results

SOC maps with four mapping approaches were generated as follows (Fig. 4). All maps show the same high value area in the north of the watershed. Apart from this, the maps estimated and produced by diverse methods differ significantly.

The SOC map produced by OK (Fig. 4a) shows a smooth surface, there is only difference between the north area and the south area, but the predicted SOC values are so flat, their difference among various land-use types cannot be distinguished easily.

The SOC map estimated by RK (Fig. 4c) is more detailed than OK, it can be seen from the map that the SOC content in shrub land and forestland is higher than other land-use types, and that in the wild grassland is low. It means that the SOC map estimated by RK can match the land-use map by and large.

The SOC maps derived from the OK_LU (Fig. 4b) and SoLIM (Fig. 4d) maps are influenced significantly by the environmental variables and reveal more detailed information and showed clearer variations with terrain and other environmental variables than OK and RK. Furthermore, the SOC map predicted by OK_LU matched the land-use map better and more detailed, the SOC map produced from SoLIM method seems more complicated and heterogeneous since it takes nine variables into account. The blank areas are water bodies and construction land where there is no sample.

\section{Validation results}

For each method, the prediction errors based on the validation dataset among three times did not see obviously difference. Therefore, we took the mean values of the three times' results as the final results as displayed in Table 5. It is shown that the OK_LU and SoLIM methods performed better than the other two methods in terms of smaller RMSE, MAPE and higher $G$ values.

In this study, RK is superior to OK for it incorporates spatial dependence in residuals and removes the trend. However, RK demands a fine regression function with high 
$R^{2}$, and the $R^{2}$ of this study is not so high $\left(R^{2}=0.278\right.$, $0.258,0.261$ ), there are only three variables absorbed into each regression function and other variables are ignored. Therefore, the prediction of RK did not show better performance than SoLIM and OK_LU.

For the present study, the SoLIM ( $G=0.886$, VAF $\left.\%=75 \%, \quad \operatorname{Adj} . R^{2}=0.537\right) \quad$ and OK_LU $\left(G=0.878, \quad\right.$ VAF $\%=72 \%$, Adj. $\left.R^{2}=0.519\right)$ method have higher $\mathrm{G}$ values as compared with $\mathrm{OK}(G=0.791$, VAF $\%=57 \%$, Adj. $\left.R^{2}=0.326\right)$ and RK $(G=0.794$, VAF $\%=61 \%, \quad$ Adj. $\left.R^{2}=0.278\right)$, while the SoLIM $(\mathrm{MAPE}=0.060, \mathrm{RMSE}=0.315)$ and OK_LU (MAPE $=$ 0.052 , RMSE $=0.329$ ) methods have lower MAPE and RMSE values than OK (MAPE $=0.250$, RMSE $=0.520$ ) and RK (MAPE $=0.124$, RMSE $=0.448)$. The validation results show that the SoLIM and OK_LU methods have lower prediction errors and their predicted values and measured values are more consistent than $\mathrm{OK}$ and $\mathrm{RK}$.

\section{Discussion}

\section{Methods comparison}

Multiple approaches have been used for analyzing spatial variations of SOC content in general, nevertheless, no single approach is suitable universally because of the spatial variability which exists in soil properties (Hengl et al. 2004; Miao et al. 2012). Here, we selected four approaches to compare each other and to explore suitable methods for mapping the SOC content of the surface $30-\mathrm{cm}$ soil in our study area of semi-arid Loess Plateau, which has a complex hilly-gully terrain.

OK is a distance-based interpolation method, which may have many practical problems when using in a complex terrain area like our study site and it is then difficult to produce a reliable prediction as proved by $\mathrm{Yao}$ et al. (2013). Its application is restricted in the study area where Grain-for-Green Project took place and variation trend of SOC content is largely influenced by the complex landscape. Besides that no auxiliary was used, the accuracy of $\mathrm{OK}$ is the worst among all the methods.

OK_LU makes good use of the land-use type information to interpolate SOC variations because SOC content of six land-use types is significantly different as revealed in Table 3, which indicates that land-use type influences the distribution of the SOC greatly. The validation results showed that the addition of land-use type in OK_LU improved the interpolating accuracies compared to the $\mathrm{OK}$ method. The OK_LU method effectively captures this dominating characteristic for combining environmental variable of land-use type and kriging model together. Its performance assessment evidently confirmed that this hybrid interpolation method was more suitable and accurate for the region of complex terrain as a simple and convenient method.

The RK was always considered to be superior to approaches only based on auto-correlation such as ordinary kriging (Ge et al. 2007a; Kumar and La 2011). RK uses both correlations between the target variable and its covariates, and the spatial auto-correlation in residuals of the SOC content to improve the estimations so that its precision of prediction is better than OK. However, one of the major limitations of RK is that this approach assumes that covariates should have constant physical relationship with the target variable in all parts of the study area, which however not always be possible in real cases (Hengl et al. 2007). RK also assumes the constant trend over the space, which did not appear in our study. When a strong relationship exists between target soil properties and auxiliary variables, RK will be accurate for interpolating soil properties studied, otherwise, OK was better (Zhu and Lin 2010). In this study, RK is medium in mapping of SOC as it does not fit the data in this study area.

The success of SoLIM relies highly on whether the selected environmental covariates relate spatial variations of soil properties (Liu and Zhu 2009; Yang et al. 2011; Zhu et al. 2001). This study supports the conclusion that when some easily measured soil covariates, which affect the SOC distribution such as land-use type, topographic parameters, and surface area ratio (SAR) were put into the SoLIM model, a high accuracy SOC map can be generated. The comparison with other Kriging methods showed that the SoLIM method could be a suitable and efficient method for predicting SOC for the Loess Plateau of China with similar environment conditions as the study area.

\section{Methods limitations}

Soil erosion induced by rainfall events in terrestrial ecosystems, as an important global environmental problem, significantly impacts on environmental quality and soil properties (Gao et al. 2014). The movement of SOC during erosion and deposition events represents a major perturbation to the terrestrial carbon cycle (Gao et al. 2013b; Sanderman and Chappell 2013).

The Loess Plateau is one of the regions in the world that suffered from severe soil erosion. The acceleration of soil erosion by water in response to the anthropogenic modification of landscapes is a serious threat to natural ecosystem functionalities, because of the loss of invaluable constituents such as SOC (Gao et al. 2012; Miao et al. 2011). In the past decades, restoration projects were implemented to improve soil erosion control in the region. The Grain-toGreen project, converting slope croplands into forest or grasslands, launched in 1999 was the most massive one (Fu 
et al. 2011). Although many research indicated that soil erosion control capacity was significantly improved in parts of the zone since 2000 as a result of vegetation restoration, soil erosion is still one of the top environmental problems that need more ecological restoration efforts (Gao et al. 2011).

Due to the soil erosion, the SOC content decreased in the slope cropland, and it increased in the dam land, this trend can be reflected in the interpolation maps of this study that the dam land has a higher SOC value than the slope cropland. Many observations have also shown that substantial $\mathrm{C}$ accumulation can occur in vegetation and soils after the establishment of plantations (Fornara and Tilman 2008; Gao et al. 2013a; Pinard and Cropper 2000). Just as in our study, the shrubland and forestland have higher SOC content than other land-use types. On account of that erosion is a major factor that adversely affects SOC sequestration at eroded sites, thus the SOC erosion and deposition must be considered in estimating the SOC. If one corroded sample was used as a training sample while the other non-corroded sample was used as a validation sample in an interpolation method, then the true SOC content will be underestimated. The reverse would be true if erosion not occurred at both training dataset sites and validation dataset sites (Sanderman et al. 2009). It means that a model calibrated to a site with a history of soil erosion when applied to a site not experiencing erosion will underestimate the SOC (Sanderman and Baldock 2010). It is evident from some analysis (Sanderman and Chappell 2013) that explicit recognition of soil redistribution can impact the successful monitoring of SOC. The effects of soil redistribution affected by erosion and deposition will be then incorporated within these SOC interpolation models in the future research.

\section{Conclusion}

We compared four methods, including OK, OK_LU, RK and SoLIM, to predict the spatial distribution of SOC in a $2.02 \mathrm{~km}^{2}$ hilly-gully watershed in the semi-arid Loess Plateau. Auxiliary environmental variables such as the land-use type information, topographic parameters were used to assist soil interpolation in this study. Two main conclusions can be drawn from the study:

1. The use of easily obtained environmental covariates, the land-use type and terrain variables in this study, which control most of the SOC variations, usually can improve accuracies of soil mapping. These variables can be very helpful to map SOC in similar watersheds of complex terrain and land-use types in the Loess Plateau, since this study area is very typical in the Loess Plateau.
2. SoLIM and OK_LU can be two suitable and efficient methods when mapping spatial variations of SOC content in watersheds like our study area in the Loess Plateau.

Acknowledgments This work was supported by the National Natural Science Foundation of China (40925003, 40901098, 41001298) and by the Youth Innovation Promotion Association, CAS.

\section{References}

Aamodt A, Plaza E (1994) Case-based reasoning-foundational issues, methodological variations, and system approaches. $\mathrm{Ai}$ Commun 7:39-59

Ahmed S, Demarsily G (1987) Comparison of geostatistical methods for estimating transmissivity using data on transmissivity and specific capacity. Water Resour Res 23:1717-1737. doi:10.1029/ WR023i009p01717

Basaran M, Erpul G, Tercan AE, Canga MR (2008) The effects of land use changes on some soil properties in Indagi Mountain Pass-Cankiri, Turkey. Environ Monit Assess 136:101-119. doi:10.1007/s10661-007-9668-4

Bi $\mathrm{H}$ et al (2008) Spatial dynamics of soil moisture in a complex terrain in the semi-arid Loess Plateau region, China. J Am Water Resour Assoc 44:1121-1131. doi:10.1111/j.1752-1688.2008. 00236.x

Cambardella CA, Karlen DL (1999) Spatial analysis of soil fertility parameters. Precis Agric 1:5-14. doi:10.1023/a:1009925919134

Cambardella CA, Moorman TB, Novak JM, Parkin TB, Karlen DL, Turco RF, Konopka AE (1994) Field-scale variability of soil properties in central Iowa soils. Soil Sci Soc Am J 58:1501-1511

Chen LD, Lu YH, Tian HY, Shi Q (2007) Principles and methodology for ecological rehabilitation and security pattern design in key project construction Yingyong. Acta Ecol Sinica 18:674-680

Chowdhury M, Alouani A, Hossain F (2010) Comparison of ordinary kriging and artificial neural network for spatial mapping of arsenic contamination of groundwater stochastic. Environ Res Risk Assess 24:1-7. doi:10.1007/s00477-008-0296-5

Ersahin S (2003) Comparing ordinary kriging and cokriging to estimate infiltration rate. Soil Sci Soc Am J 67:1848-1855

Fornara D, Tilman D (2008) Plant functional composition influences rates of soil carbon and nitrogen accumulation. J Ecol 96:314-322

Fu BJ (1989) Soil-erosion and its control in the Loess Plateau of China. Soil Use Manag 5:76-82. doi:10.1111/j.1475-2743.1989. tb00765.x

Fu BJ, Wang YF, Lu YH, He CS, Chen LD, Song CJ (2009) The effects of land-use combinations on soil erosion: a case study in the Loess Plateau of China. Prog Phys Geogr 33:793-804. doi:10.1177/0309133309350264

Fu BJ, Liu Y, Lü YH, He CS, Zeng Y, Wu B (2011) Assessing the soil erosion control service of ecosystems change in the Loess Plateau of China. Ecol Complex 8:284-293

Gao Y, Zhong B, Yue H, Wu B, Cao S (2011) A degradation threshold for irreversible loss of soil productivity: a long-term case study in China. J Appl Ecol 48:1145-1154

Gao Y, Zhu B, Wang T, Wang Y (2012) Seasonal change of nonpoint source pollution-induced bioavailable phosphorus loss: a case study of Southwestern China. J Hydrol 420:373-379

Gao Y, He N, Wang Q, Miao C (2013a) Increase of external nutrient input impact on carbon sinks in Chinese Coastal Seas. Environ Sci Technol 47:13215-13216 
Gao Y, Yu G, He N (2013b) Equilibration of the terrestrial water, nitrogen, and carbon cycles: advocating a health threshold for carbon storage. Ecol Eng 57:366-374

Gao Y, Zhu B, Yu G, Chen W, He N, Wang T, Miao C (2014) Coupled effects of biogeochemical and hydrological processes on $\mathrm{C}, \mathrm{N}$, and $\mathrm{P}$ export during extreme rainfall events in a purple soil watershed in southwestern China. J Hydrol 511:692-702

Ge Y, Morgan CLS, Thomasson JA, Waiser T (2007a) A new perspective to near-infrared reflectance spectroscopy: a wavelet approach. Transact Asabe 50:303-311

Ge Y, Thomasson JA, Morgan CL, Searcy SW (2007b) VNIR diffuse reflectance spectroscopy for agricultural soil property determination based on regression-kriging. Transact Asabe 50:1081-1092

Goovaerts P, AvRuskin G, Meliker J, Slotnick M, Jacquez G, Nriagu J (2005) Geostatistical modeling of the spatial variability of arsenic in groundwater of southeast Michigan. Water Resour Res 41:W07013. doi:10.1029/2004wr003705

Grace J, Williams M (2004) Understanding and parameterizing the soil-water-atmosphere transfer through vegetation vol 6 . Unsaturated-zone modeling: progress, challenges and applications. Springer, Dordrecht

Hengl T, Heuvelink GBM, Stein A (2004) A generic framework for spatial prediction of soil variables based on regression-kriging. Geoderma 120:75-93. doi:10.1016/j.geoderma.2003.08.018

Hengl T, Heuvelink GBM, Rossiter DG (2007) About regressionkriging: from equations to case studies. Comput Geosci 33:1301-1315. doi:10.1016/j.cageo.2007.05.001

Hosseini E, Gallichand J, Marcotte D (1994) Theoretical and experimental performance of spatial interpolation methods for soil-salinity analysis. Transact Asae 37:1799-1807

Hu K, Li H, Li B, Huang Y (2007) Spatial and temporal patterns of soil organic matter in the urban-rural transition zone of Beijing. Geoderma 141:302-310. doi:10.1016/j.geoderma.2007.06.010

Huang Ping LTX, Zhang JB, Liao GT (2009) Effects of slope's gradient and aspect on spatial heterogeneity of soil organic matter in low mountainous region. Soils 41:264-268

Hudson BD (1992) The soil survey as paradigm-based science. Soil Sci Soc Am J 56:836-841

Jenness JS (2004) Calculating landscape surface area from digital elevation models. Wildl Soc Bull 32:829-839

Kravchenko A, Bullock DG (1999) A comparative study of interpolation methods for mapping soil properties. Agron J 91:393-400

Kumar S, La R (2011) Mapping the organic carbon stocks of surface soils using local spatial interpolator. J Environ Monit 13:3128-3135. doi:10.1039/c1em10520e

Kupfersberger H, Deutsch CV, Journel AG (1998) Deriving constraints on small-scale variograms due to variograms of largescale data. Math Geol 30:837-852. doi:10.1023/a: 1021726609413

Lado LR, Polya D, Winkel L, Berg M, Hegan A (2008) Modelling arsenic hazard in Cambodia: a geostatistical approach using ancillary data. Appl Geochem 23:3010-3018. doi:10.1016/j. apgeochem.2008.06.028

Lal R (2004) Soil carbon sequestration to mitigate climate change. Geoderma 123:1-22. doi:10.1016/j.geoderma.2004.01.032

Li J, Heap AD (2011) A review of comparative studies of spatial interpolation methods in environmental sciences: performance and impact factors. Ecol Inf 6:228-241. doi:10.1016/j.ecoinf. 2010.12.003

Lian Gang GX-d, Fu B-j, Hu C-x (2006) Spatial variability and prediction of soil organic matter at county scale on the Loess Plateau. Prog Geogr 25:112-122

Lin GF, Chen LH (2004) A spatial interpolation method based on radial basis function networks incorporating a semivariogram model. J Hydrol 288:288-298. doi:10.1016/j.jhydrol.2003.10. 008

Liu J, Zhu AX (2009) Mapping with words: a new approach to automated digital soil survey international. J Intell Syst 24:293-311. doi:10.1002/int.20337

Liu F, Geng X, Zhu AX, Fraser W, Waddell A (2012) Soil texture mapping over low relief areas using land surface feedback dynamic patterns extracted from MODIS. Geoderma 171:44-52. doi:10.1016/j.geoderma.2011.05.007

Marquínez J, Lastra J, García P (2003) Estimation models for precipitation in mountainous regions: the use of GIS and multivariate analysis. J Hydrol 270:1-11

McBratney AB, Santos MLM, Minasny B (2003) On digital soil mapping. Geoderma 117:3-52. doi:10.1016/s00167061(03)00223-4

Miao CY, Yang L, Liu BY, Gao Y, Li SL (2011) Streamflow changes and its influencing factors in the mainstream of the Songhua River basin, Northeast China over the past 50 years. Environ Earth Sci 63:489-499. doi:10.1007/s12665-010-0717-x

Miao CY, Yang L, Chen XH, Gao Y (2012) The vegetation cover dynamics (1982-2006) in different erosion regions of the Yellow River Basin, China Land. Degrad Dev 23:62-71. doi:10.1002/ ldr. 1050

Minasny B, McBratney AB (2007) Spatial prediction of soil properties using EBLUP with the Matern covariance function. Geoderma 140:324-336. doi:10.1016/j.geoderma.2007.04.028

Mirbagheri M, Barbeau H, Kearney R (2000) Intrinsic and reflex contributions to human ankle stiffness: variation with activation level and position. Exp Brain Res 135:423-436

Mueller TG, Pierce FJ (2003) Soil carbon maps: enhancing spatial estimates with simple terrain attributes at multiple scales. Soil Sci Soc Am J 67:258-267

Pei T, Qin CZ, Zhu AX, Yang L, Luo M, Li BL, Zhou CH (2010) Mapping soil organic matter using the topographic wetness index: a comparative study based on different flow-direction algorithms and kriging methods. Ecol Indic 10:610-619. doi:10. 1016/j.ecolind.2009.10.005

Perry M, Niemann J (2008) Generation of soil moisture patterns at the catchment scale by EOF interpolation. Hydrol Earth Syst Sci 12:39-53

Pinard M, Cropper W (2000) Simulated effects of logging on carbon storage in dipterocarp forest. J Appl Ecol 37:267-283

Qi F, Zhu AX (2003) Knowledge discovery from soil maps using inductive learning International. J Geogr Inf Sci 17:771-795. doi:10.1080/13658810310001596049

Qin C, Zhu AX, Pei T, Li B, Zhou C, Yang L (2007) An adaptive approach to selecting a flow-partition exponent for a multipleflow-direction algorithm international. J Geogr Inf Sci 21:443-458. doi:10.1080/13658810601073240

Qiu Y, Fu B, Wang J, Chen LD (2004) Space-time change of soil nutrients and its impact factors in the loess plateau watershed. Prog Nat Sci 14(3):294-299

Robinson TP, Metternicht G (2006) Testing the performance of spatial interpolation techniques for mapping soil properties. Comput Electron Agric 50:97-108. doi:10.1016/j.compag.2005. 07.003

Sanderman J, Baldock JA (2010) Accounting for soil carbon sequestration in national inventories: a soil scientist's perspective. Environ Res Lett 5:034003

Sanderman J, Chappell A (2013) Uncertainty in soil carbon accounting due to unrecognized soil erosion. Glob Change Biol 19:264-272

Sanderman J, Farquharson R, Baldock J (2009) Soil carbon sequestration potential: a review for Australian agriculture. CSIRO Land and Water, Australia, pp viii +80 
Sigua GC, Hudnall WH (2008) Kriging analysis of soil propertiesimplication to landscape management and productivity improvement. J Soils Sediments 8:193-202. doi:10.1007/s11368-0080003-7

Tramblay Y, Bouvier C, Martin C, Didon-Lescot J-F, Todorovik D, Domergue J-M (2010) Assessment of initial soil moisture conditions for event-based rainfall-runoff modelling. J Hydrol 387:176-187

Viscarra Rossel RA, McBratney AB (1998) Soil chemical analytical accuracy and costs: implications from precision agriculture Australian. J Exp Agric 38:765-775

Wang Y, Fu B, Lue Y, Song C, Luan Y (2010) Local-scale spatial variability of soil organic carbon and its stock in the hilly area of the Loess Plateau, China. Quatern Res 73:70-76. doi:10.1016/j. yqres.2008.11.006

Yang L, Jiao Y, Fahmy S, Zhu AX, Hann S, Burt JE, Qi F (2011) Updating conventional soil maps through digital soil mapping. Soil Sci Soc Am J 75:1044-1053. doi:10.2136/sssaj2010.0002

Yao X, Fu B, Lü Y, Chang R, Wang S, Wang Y, Su C (2012) The multi-scale spatial variance of soil moisture in the semi-arid Loess Plateau of China. J Soils Sediments 12:694-703
Yao X, Fu B, Lu Y, Sun F, Wang S, Liu M (2013) Comparison of Four Spatial Interpolation Methods for Estimating Soil Moisture in a Complex Terrain Catchment. Plos One 8 doi:10.1371/ journal.pone.0054660

Zhong YP, Tang J, Wang L (2006) Distribution characteristic of soil organic carbon in three gorges reservior district. J Soil Water Conserv 20:73-76

Zhou Bin XH-W, Wang R-C (2003) Soil organic matter mapping based on classification tree modeling. Acta Pedol Sinica 40:801-808

Zhu Q, Lin HS (2010) Comparing ordinary kriging and regression kriging for soil properties in contrasting landscapes. Pedosphere 20:594-606

Zhu AX, Band L, Vertessy R, Dutton B (1997) Derivation of soil properties using a soil land inference model (SoLIM). Soil Sci Soc Am J 61:523-533

Zhu AX, Hudson B, Burt J, Lubich K, Simonson D (2001) Soil mapping using GIS, expert knowledge, and fuzzy logic. Soil Sci Soc Am J 65:1463-1472 